\title{
Psychometric PROPERTIES OF THE EXPERIENCE OF WORK AND LifE Circumstances Questionnaire and the Hopkins Symptom Checklist
}

\section{Authors:}

Rudolf M. Oosthuizen ${ }^{1}$

Pieter Koortzen ${ }^{2}$

\section{Affiliations: \\ ${ }^{1}$ Department of Industrial and Organisational \\ Psychology, University of South Africa, South Africa \\ ${ }^{2}$ Resolve Encounter \\ Consulting, South Africa}

Correspondence to:

Rudolf M. Oosthuizen

e-mail:

oosthrm@unisa.ac.za

Postal address:

PO Box 392, UNISA, 0003, South Africa

\section{Keywords:}

job stress;

family stress;

Experience of Work

and Life Circumstances

Questionnaire; Hopkins

Symptom Checklist;

psychological well-being

\section{Dates:}

Received: 05 June 2008

Accepted: 13 Nov. 2008

Published: 20 Apr. 2009

How to cite this article:

Oosthuizen, R.M., \&

Koortzen, P. (2009).

Psychometric properties of the Experience of Work and Life Circumstances Questionnaire and the

Hopkins Symptom Checklist. SA Journal of Industrial Psychology/SA Tydskrif vir Bedryfsielkunde, 35(1), Art. \#492, 10 pages.

DOI: 10.4102/sajip.v35i1.492

This article is available at: http://www.sajip.co.za

(c) 2009. The Authors. Licensee: OpenJournals Publishing. This work is licensed under the Creative Commons Attribution License.

\section{ABSTRACT}

The aim of this research was to investigate the reliability and validity of the Experience of Work and Life Circumstances Questionnaire and the Hopkins Symptom Checklist when administered to a convenience sample of 241 fire-fighters from a metropolitan municipality. The results indicate that these two measuring instruments yielded acceptable internal-consistency reliability coefficients for most of the subscales of the questionnaires. Construct validity was investigated by means of exploratory factor analysis. It was concluded that the measuring instruments are fit to be used for diagnostic and developmental purposes and during counselling to enhance the psychological wellbeing of fire-fighters and their families.

\section{INTRODUCTION}

Fire-fighters are subject to and experience intense job stress due to the emergency services that they render to the public (Kaminsky, McCabe, Langlieb \& Everly, 2007). Owing to their high level of exposure to traumatic incidents, fire-fighters can become secondary victims of trauma, exhibiting symptoms akin to those of direct victims (Rogers, 2007). Job stress may be the result of certain job stressors, which may result in certain job-stress symptoms and reactions in fire-fighters. Occupational-health research has advanced beyond an exclusive focus on physical hazards in the workplace to broader concepts of health that embrace the psychosocial dimensions of work: '[T]he social environment at work, organisational aspects of the job and certain operational aspects of the task performed' (Sauter, Murphy \& Hurrel, 1990).

Occupational-stress researchers from the United States of America (USA) and Europe (especially Sweden) have examined how the specific characteristics of jobs affect mental health (such as depression, anxiety and general mental-distress symptoms) and physical outcomes (such as heart disease, ulcers and chronic pain) (Piltch, Walsh, Mangione \& Jennings, 1994).

Increasingly, such research has focused on two resources, namely social support and job control, as the potential moderators of the effect of work-related demands and pressures on the mental and physical health of fire-fighters. Social support in respect of work includes help that fire-fighters receive from supervisors, co-workers, spouses, friends and relatives. Control, in general, is the ability to exert some influence over one's environment so that the environment becomes more rewarding or less threatening. Job control is the ability to influence the planning and execution of work tasks. Unlike measures of personal control, which focus on the personalities of fire-fighters, job control focuses on how the organisation of work may or may not provide the resources necessary for fire-fighters to meet the demands of their work (De Jonge, Dollard, Dormann, Le Blanc \& Houtman, 2000).

One of the challenges when conducting research on the stress and stress reactions or symptoms of fire-fighters is to use reliable and valid instruments. Because very few specific instruments have been developed for this group, researchers routinely use generic stress questionnaires. Although results obtained with such instruments generally appear to be in line with international research, it is important to determine whether such instruments are reliable and valid in the South African context. This research therefore focuses on establishing whether the Experience of Work and Life Circumstances Questionnaire (Van Zyl \& Van der Walt, 1991) and the Hopkins Symptom Checklist (Derogatis, Lipman, Rickles, Uhlenhuth \& Covi, 1974) are reliable and valid when used for a South African group of firefighters.

The supportive theory of the instruments is discussed first.

A theoretical model that is still being used extensively to measure the effects of job content on the health and well-being of fire-fighters is the job-strain model developed by Robert Karasek (1979) and colleagues in Sweden some decades ago. This two-dimensional model locates the primary source of job stress within the task demands of the job itself. Jobs that simultaneously present heavy psychological demands and restrict the options of fire-fighters to respond to those demands (jobs high in demand and low in decision latitude or 'control', for example) are seen as potentially stressful (Daniels, 1999).

Decision latitude includes control over both the use of one's abilities (skill direction) and the way in which work is accomplished (skill authority). Psychological job demands include factors such as time pressure, deadline stress, heavy workload and conflicting demands. Karasek's measures of job demands and control were originally derived from the United States Quality of Employment Survey administered in 1969, 1972 and 1977. In early analyses, the model was used to test the relationship between selfreported measures of job demands and control and mental strain (exhaustion and depression) in male workers in the USA and Sweden (Karasek, 1979). The United States (US) data came from the 1972 and 1977 Quality of Employment Survey; the Swedish sample came from longitudinal national surveys of workers conducted in 1968 and 1974. The US study showed fourfold variation in high-strain jobs (the highdemand and low-control group) and in low-strain jobs (high in control and low in demand). Furthermore, both the US and Swedish samples showed fourfold variation in exhaustion between the high-strain and 
the low-strain workers (Van der Doef \& Maes, 1999; Piltch et al., 1994).

In the job-strain model, fire-fighters are classified into quadrants on the basis of the level of control that they experience. The model is interactive because the impact of job demands is moderated by job control. High-strain jobs are expected to produce higher levels of mental and physical distress than lowstrain jobs, active jobs (high demand and high control) or passive jobs (low in demand and low in control). Two hypotheses are suggested by the model, one each along the major and minor diagonals in the $2 \times 2$ table: (a) in both cells where demands are relatively greater than control, mental and physical distress occur (Diagonal A); and (b) where demands and control are both high, active learning should result, whereas, when they are both low, skills atrophy (Diagonal B) (Karasek, 1979).

\section{Job stressors}

Causes of job stress are depicted as job stressors. According to literature, two major job stressors can be identified, namely (1) stressors arising outside the working situation and (2) stressors originating within the working situation (Catellano \& Plionis, 2006; Ussery \& Waters, 2006). Both these dimensions should be evaluated in the study of the stress levels of fire-fighters.

\section{These two dimensions are conceptualised as follows:}

\section{Stressors arising outside the working situation}

For fire-fighters, an interface appears to exist between job stressors arising outside the working situation and family stress. Stressors arising outside the working situation are characterised by marital dysfunction and divorce, limited time with family, problems with children, and lifestyle factors such as the abuse of alcohol, excessive smoking and a lack of exercise (Morash, Haarr \& Kwak, 2006; Roberts \& Levenson, 2001). Further issues include long shifts (which interfere with sex life), a loss of friends (who are not fire-fighters), the suicide of colleagues or family members, lower social status, anger and frustration at home or in the family, emotional, intellectual and physical exhaustion, wives being alone at night, and not being available to help the family when needed (He, Zhao \& Archbold, 2002; Shakespeare-Finch, Smith \& Obst, 2002). It is not possible to evaluate the stress of fire-fighters comprehensively without evaluating this dimension of their stress.

Apart from stressors arising outside the working situation, there are also a number of stressors originating within the working situation that need to be studied and evaluated. The relationship between these stressors and the families of firefighters is also given below.

\section{Stressors originating within the working situation}

A spillover effect (job and family conflict) appears to exist between job stressors arising outside the working situation and job stressors originating within the working situation. Job stressors originating within the working situation are characterised by task characteristics, organisational functioning, physical working conditions and job equipment, career and social matters, and remuneration, fringe benefits and personnel policy.

\section{- Task characteristics}

The degree of uncertainty, exposure to human loss, interpersonal tension, shift work, overload, underload and traumatic incidents seem to be the major task characteristics that result in the spillover of conflict from job to family (Aterburn, 2001; Fishkin, 1991; Stockton, 2003; Sutherland \& Cooper, 1990). Further contributing task characteristics are accountability for decisions taken under pressure, the death of people, terrible sensory experiences (Lemanski, 2003; Regehr, Johanis, Dimitropoulos, Bartram
\& Hope, 2003), serious fires in which people are trapped, accidents in which many people are injured, the danger of injuries to and illness of fire-fighters, and slow response time (Seedat, La Grange, Niehaus \& Stein, 2003; Wiese, Rothmann \& Storm, 2003).

\section{- Organisational functioning}

The functioning of the organisation may also have the potential of negative impact on the family (Beaton, Murphy \& Pike, 2001). Uncertainty and unsafeness, and administrative stressors such as poor administrative support, a lack of leadership skill, policy and procedure, job schedules, excessive paperwork and red tape, the delegation of functions, evaluation systems and the measurement of effectivity, responsibility versus authority, a continuous focus on problems, and a lack of positive feedback emerged to be particularly pertinent (Jerling, 2002).

\section{- Physical working conditions and job equipment}

It seems as if the interface between job stressors and family functioning exists as a result of insufficient equipment and resources, physical working conditions, lightning, noise, vibration, climate, temperature, ventilation, humidity, hygiene, new technology, exposure to risk and danger, travel, shortage of human resources and the vastness of areas (Pike, 2003; Seedat et al., 2003).

\section{- Career and social matters}

Limited career and promotion opportunities, insufficient training, and failure to utilise the abilities and potential of fire-fighters optimally appear to be the major career matters that result in the spillover of conflict from job to family (Mitchell \& Bray, 1990; Volpe, 2000). Contributing social matters are long or unusual working hours, absenteeism, the attitude of hospital personnel, place of residence, conflict with colleagues, offensive and intoxicated or poisoned patients, media on the scene, pressure to conform with the group, and lack of privacy (Torres, Maggard \& Torres, 2003).

- Remuneration, fringe benefits and personnel policy Compensation and employee benefits may have the potential of negative impact on the family. The lack of social status, low salaries and low expectations emerged to be particularly pertinent (Fontana, 1994; Lemanski, 2003).

The Experience of Work and Life Circumstances Questionnaire on which we focus in this article measures both theoretical dimensions, namely stressors arising outside the work situation and stressors originating within the work situation (Van Zyl \& Van der Walt, 1991). This questionnaire may therefore be an appropriate method of evaluating the stress levels of fire-fighters. Apart from measuring the dimensions of stressors, researchers and counsellors often also evaluate the symptomology of firefighters. This is presented in the following section.

\section{Job-stress symptoms and reactions}

Job-stress symptoms and reactions in fire-fighters are characterised by somatic symptoms, obsessive-compulsive behaviour, interpersonal sensitivity, depression and anxiety.

\section{Somatic symptoms}

Continuous exposure to job stressors over a long period may cause certain somatic symptoms in fire-fighters (Barlow, 2002). The spillover of conflict from job to family becomes evident when fire-fighters are preoccupied with the belief that they have a serious disease, yet no evidence of physical abnormality can be found (Change this bracket to (Linienfeld, 1998; Nevid, Rathus \& Greene, 2003). Marriage partners may become very concerned over the physical condition of the fire-fighters and anxious that no medical treatment seems to be helping. This may cause a lot of stress for the marriage partners and for the children (Smith, Manning \& Petruzzello, 2001). 


\section{Obsessive-compulsive behaviour}

Obsessive-compulsive behaviour in fire-fighters may also be the result of continuous exposure to job stressors over a long period. Obsessions may be potent and persistent enough to interfere with daily life and may engender significant distress and anxiety. Such behaviour may include doubts, impulses and mental images (Nevid, Rathus \& Greene, 2005). For example, a fire-fighter may wonder endlessly whether or not she or he has locked the doors and shut the windows. The spillover of conflict from job to family becomes evident when fire-fighters become obsessed with the impulse to harm their spouses. Checking rituals, such as repeatedly checking that the doors are securely locked before leaving the house, cause delays and annoy marriage partners and children, and cleaning may occupy several hours a day (Davison, Neale \& Kring, 2004).

\section{Interpersonal sensitivity}

Continuous exposure to job stressors over a long period may furthermore cause fire-fighters to become oversensitive in their interpersonal relationships with their marriage partners and their children (Plug, Meyer, Louws \& Gouws, 1991). The spillover of conflict from job to family becomes evident when fire-fighters tend to fear rejection, disapproval, neglect and other adverse interpersonal situations with their marriage partners because of the perceived threat to their self-definition (Gmelch \& Chan, 1994).

\section{Depression}

For some fire-fighters, the combination of life's calamities coupled with continuous exposure to job stressors over a long period may also become too much to bear (Monnier, Cameron, Hobfoll \& Gribble, 2000). The result is often a breakdown of psychological defences. This may lead to the downward mental and emotional spiral of despair and ultimately to the emotional state of depression, from which the road to recovery is often painful and difficult (Elliott, Goldberg, Duncan \& Kuehl, 2004). The spillover effect (job and family conflict) manifests itself when fire-fighters experience depression, the result of having no control over working conditions and environment. Uncertainty and unsafeness due to organisational changes may intensify this feeling of hopelessness. Such feelings may cause fire-fighters to become emotionally inaccessible to their families (Fishkin, 1992).

\section{Anxiety}

Continuous exposure to job stressors over a long period may also cause fire-fighters to experience anxiety reactions. They may experience physical features of anxiety, such as trembling or a shaking of hands or limbs, heavy perspiration, a shortness of breath or shallow breathing, a pounding or racing heart, dizziness, weakness or numbness, stiffness in the neck or back, an upset stomach or nausea, diarrhoea, and a feeling of irritability or of being on edge (Davison et al., 2004). Behavioural features of anxiety may include avoidance behaviour, clinging behaviour, dependent behaviour and agitated behaviour. Cognitive features of anxiety may include worrying about something and a nagging sense of dread or apprehension about the future. The spillover effect (job and family conflict) manifests when the marriage partners of fire-fighters feel that they are unable to cope with these anxieties and that they do not know how to help (Nevid et al., 2005).

The Hopkins Symptom Checklist that we use in this article measures the above theoretical dimensions and therefore appears to be an appropriate method of assessing the psychological symptoms of fire-fighters (Derogatis et al., 1974). Descriptions of the Experience of Work and Life Circumstances Questionnaire and the Hopkins Symptom Checklist are presented in the following section. In view of the above models of job stressors and stress symptoms, combined with the unique working conditions of fire-fighters, the aim of this research was to assess the reliability and construct validity of the Experience of Work and Life Circumstances Questionnaire and the Hopkins Symptom Checklist for a population of firefighters.

\section{RESEARCH DESIGN}

\section{Research approach}

A survey design enabling the quantitative measurement and statistical analysis of job and family stress was used.

\section{Research method Sample}

A convenience sample consisting of 241 fire-fighters was drawn from the population of fire-fighters attached to a metropolitan municipality. The fire-fighters were volunteers recruited from various fire brigades to participate in the empirical investigation. They consisted of single, married and divorced females and males from different population, language and age groups. A distinction was made among the following ranks of fire-fighters: learner fire-fighter, grades 1-11; junior fire-fighter; senior fire-fighter; leading fire-fighter; station officer; and divisional officer.

\section{Measuring instruments}

Experience of Work and Life Circumstances Questionnaire

The Experience of Work and Life Circumstances Questionnaire was introduced in 1991 (Van Zyl \& Van der Walt, 1991). The questionnaire was developed to include different stress reactions and not only anxiety. Van Graan (1981) states that stress is a subjective emotional experience consisting of different reactions, not only anxiety (Van Zyl \& Van der Walt, 1991). The questionnaire is based on the experiences and causes of job stress. A high level of stress experience is indicated when a fire-fighter obtains a high score on the questionnaire due to problems from the environment (Van Zyl \& Van der Walt, 1991).

The questionnaire can be utilised for the measurement of stress levels experienced and of the nature of the important causes of stress in fire-fighters. The minimum educational requirement for respondents was grade 10 . The results can also be utilised to identify fire-fighters who are functioning under high levels of stress and to determine the main stressors in their environments. The questionnaire can furthermore be utilised by industrial psychologists during counselling and to enhance the psychological well-being of fire-fighters and their families (Van Zyl \& Van der Walt, 1991). This self-assessment questionnaire consists of two parts, namely experience of the job and circumstances and expectations of the job.

- The first part of the questionnaire, which measures the way in which the job is experienced, indicates the level of stress (subscale 1) of the fire-fighter and whether the firefighter is experiencing stress at normal, high or very high levels. Scale A of the questionnaire consists of 40 items, each measured on a five-point scale that indicates how often certain stress emotions (such as depression, anxiety and frustration) occur. A high score indicates a high level of stress (Van Zyl \& Van der Walt, 1991).

- The second part of the questionnaire, which measures the circumstances and expectations of the job, indicates the level of stress experienced by the fire-fighter in this respect. Questions are also answered on a five-point scale (Scale B in the case of circumstances and Scale C in the case of expectations) to indicate how often specific emotions occur. A total of 76 items pertains to fire-fighters' circumstances and unfulfilled expectations. Circumstances as a possible cause of stress may arise outside the working 
situation (subscale 2). Causes originating within the work situation are characterised by the following dimensions: task characteristics (subscale 3), organisational functioning (subscale 4), physical working conditions and job equipment (subscale 5), social matters (subscale 6), career matters (subscale 7) and remuneration, fringe benefits and personnel policy (subscale 8) (Van Zyl \& Van der Walt, 1991).

The questionnaire can be administered either in an individual or in a group context. The test material consists of a questionnaire booklet available both in Afrikaans and in English. Answers are indicated on a separate answer sheet. Three categories are distinguished and scores reflect the levels, as well as the causes of stress, as normal, high or very high. To facilitate interpretation, guidelines are provided for interpreting scores as normal, high or very high.

The questionnaire is assumed to have content validity because the items were developed according to a theoretical model and evaluated by a panel of experts. In the course of its development, the recommended three steps to be followed to attain logical validity as described by Raftery, Tanner \& Wells (2002) were followed. From results obtained from the steps, Van Zyl and Van der Walt (1991) came to the conclusion that the questionnaire demonstrates logical validity.

With regard to construct validity, Van Zyl and Van der Walt (1991) report correlations among the various fields or scales of the questionnaire, ranging between 0,05 and 0,72 (absolute values). Further evidence regarding construct validity was obtained by correlating scale totals with the relevant factors of the 16PF questionnaire (Forms A and E) (Cattell, Eber \& Tatsuoka, 1970) and the PHSF relationships questionnaire (Fouché \& Grobbelaar, 1971), correlations varying between 0,00 and 0,46 .

The reliability estimates for the scales of the Experience of Work and Life Circumstances Questionnaire appeared to be satisfactory. Internal-consistency reliability coefficients for the questionnaire scales, as measured by Kuder-Richardson Formula 8, ranged from 0,83 to 0,92 . The obtained test/retest reliabilities varied from 0,62 to 0,80 (Van Zyl \& Van der Walt, 1991).

\section{Hopkins Symptom Checklist}

The Hopkins Symptom Checklist is a self-report symptom inventory developed for fire-fighters to give them an understanding of possible psychological symptoms being experienced (Derogatis et al., 1974). Gmelch (1982) states that stress symptoms manifest at five different levels: somatisation, obsessive-compulsive behaviour, interpersonal sensitivity, depression and anxiety:

- Somatisation (soma meaning 'body') reflects distress from perceptions of bodily dysfunctions, such as headaches, pain, soreness and discomfort.

- Obsessive-compulsive behaviour reflects irresistible thoughts, impulses and actions not connected to ego drives. Examples are forgetfulness, worry about carelessness, indecisiveness and difficulty concentrating.

- Interpersonal sensitivity reflects feelings of personal inadequacy and inferiority compared to others, such as being annoyed, critical of others, hot-tempered and socially insecure.

- Depression reflects feelings of low spirits and dejection. This may be revealed in a number of ways, such as losing sexual interest, wanting life to end, having a poor appetite, crying easily and feeling hopeless.

- Anxiety reflects apprehension, distress and uneasiness and typically manifests in shakiness, trembling, fear, nausea, heart palpitations and sweating (Gmelch, 1982).
Stress increases the chances of developing many illnesses. The debate, however, centres on psychosomatic illness, in other words the degree to which the mind contributes to physical ill health. Beyond the purely physiological illnesses - such as botulism, where physical factors are extreme and psychological factors nil - a vast range of diseases related to stress has been identified by physicians and researchers (Derogatis et al., 1974). Illnesses can be arranged on a continuum from purely physiological to purely psychological. Research has shown, however, that stressful events have a deleterious effect on a person's body, using up energy and making the person susceptible to common disorders. The rationale of the questionnaire is that, since it measures the occurrence of a particular stress experience of a fire-fighter, it can also be utilised to measure high intensities of stress symptoms (Gmelch, 1982).

The questionnaire consists of five dimensions (the five levels of stress symptoms discussed previously) and provides a tota score for stress. It can be administered either in an individual or in a group context.

The questionnaire consists of 45 items that focus on the measurement of the occurrence of a particular stress experience (Derogatis et al., 1974). Respondents are requested to complete each item on a 'how often' basis. Occurrence is measured through the selection by respondents of one of the following alternatives: $1=$ never; $2=$ seldom; 3 = often; and 4 $=$ almost always. There is no time limit for the completion of the questionnaire. The questionnaire is scored and interpreted in terms of the separate scores for each of the five dimensions (Gmelch, 1982).

The face validity of the questionnaire appears to be suitable for determining whether fire-fighters who are regularly subjected to crisis situations display symptoms of stress or not and for determining the intensity of the stress symptoms experienced. The authors of the instrument suggest that the questionnaire can be utilised by industrial psychologists during therapy and to enhance the psychological strength of fire-fighters and their families (Derogatis et al., 1974). No specific information on the reliability and validity of the questionnaire has been reported in literature (Gmelch, 1982). This shortcoming is rectified in this study.

\section{Data collection}

The questionnaires were administered in 12 sessions. The firefighters of the northern and southern regions were divided into three shifts. The respondents participating in each shift in the various regions were welcomed at the sessions and put at ease with the commencement of the administration of the questionnaires. They were asked to answer the questions truthfully and accurately. They were given verbal instructions regarding the completion of the questionnaires and were assured of the confidentiality of the research. It was explained to the respondents that they would be asked to complete different questionnaires designed to measure the effects of stress and that there would be no time limit. The results were discussed with the respondents where such a need was expressed.

\section{RESULTS}

\section{Reliability of the Experience of Work and Life Circumstances Questionnaire}

Table 1 indicates the internal-consistency reliabilities of the subscales of the Experience of Work and Life Circumstances Questionnaire. Cronbach alpha coefficients ranging from 0.72 to 0.92 were obtained. The coefficients were acceptable for most of the subscales, except for the task characteristics subscale, which was slightly lower than acceptable. This seems to indicate acceptable reliabilities for the subscales of the Experience of Work and Life Circumstances Questionnaire. 
TABLE 1

Percentage of variance explained by the factors extracted from the subscales of the Experience of Work and Life Circumstances Questionnaire

\begin{tabular}{lc}
\hline SUBSCALES & CRONBACH ALPHA COEFFICIENT \\
\hline Stress level & 0.92 \\
Causes arising outside the working & 0.82 \\
situation & 0.79 \\
Organisational functioning & 0.72 \\
Task characteristics & 0.82 \\
Physical working conditions and job & \\
equipment & 0.77 \\
Career matters & 0.77 \\
Social matters & 0.83 \\
Remuneration, fringe benefits and & \\
personnel policy &
\end{tabular}

TABLE 2

Percentage of variance explained by the factors extracted from the subscales of the Experience of Work and Life Circumstances Questionnaire

\begin{tabular}{|c|c|c|}
\hline SUBSCALES & $\begin{array}{r}\text { NUMBER OF } \\
\text { FACTORS RETAINED } \\
\text { BY THE MINEIGEN } \\
\text { CRITERION }\end{array}$ & $\begin{array}{r}\text { CUMULATIVE } \\
\text { PERCENTAGE } \\
\text { OF THE } \\
\text { PROPORTION }\end{array}$ \\
\hline Stress level & 11 & 63.14 \\
\hline $\begin{array}{l}\text { Causes arising outside the working } \\
\text { situation }\end{array}$ & 8 & 62.15 \\
\hline Organisational functioning & 2 & 60.24 \\
\hline Task characteristics & 5 & 56.22 \\
\hline $\begin{array}{l}\text { Physical working conditions and } \\
\text { job equipment }\end{array}$ & 1 & 47.81 \\
\hline Career matters & 2 & 51.63 \\
\hline Social matters & 1 & 42.94 \\
\hline $\begin{array}{l}\text { Remuneration, fringe benefits and } \\
\text { personnel policy }\end{array}$ & 2 & 52.05 \\
\hline
\end{tabular}

\section{Construct validity of the Experience of Work and} Life Circumstances Questionnaire

Exploratory principal-component analyses, one for each of the eight subscales of the questionnaire, were conducted to determine the number of factors underlying the intercorrelation matrices of the items. Table 2 indicates the number of factors with eigen values greater than one retained by the MINEIGEN criterion as well as the cumulative percentage of the proportion of the variance explained by each subscale of the questionnaire.

Varimax rotations to simple structure were subsequently carried out. Factor loadings greater than 0.4 were used as cutoff points and only such values are indicated in Table 3.

Stress level: Eleven factors with eigen values greater than one were retained for the stress level subscale. The percentage of variance accounted for was $63.14 \%$.

The factors indicate the following:

- Factor 1 indicates that fire-fighters often feel aggressive in their work, in other words they want to hurt someone or break something, become angry and lose their tempers.

- Factor 2 indicates that fire-fighters often feel afraid in their work without knowing whether they are afraid of a particular person and/or a situation.

- Factor 3 indicates that fire-fighters often feel uncertain in their work; it is as if they are up against a wall and simply cannot make any progress.

- Factor 4 indicates that fire-fighters often feel that no one wants to support them in their work and that their particular work situation compares unfavourably with that of others.

- $\quad$ Factor 5 indicates that fire-fighters often feel that they do not wish to participate in anything and have no real interest in their work activities.

- Factor 6 indicates that fire-fighters often feel sad in their work and are often emotionally disturbed when involved in tragic rescue operations.
- $\quad$ Factor 7 indicates that fire-fighters often feel that their views clash with those of others and that they experience conflict in their work situation.

- Factor 8 indicates that fire-fighters often feel overloaded with too much work and too many responsibilities.

- $\quad$ Factor 9 indicates that fire-fighters often feel that they have broken some or other rule and that they depend too much on help from others in their work.

- Factor 10 indicates that fire-fighters feel that they too often merely accept things as they are in their work.

- Factor 11 indicates that fire-fighters often feel that they are wary of colleagues and/or supervisors.

Causes arising outside the working situation: Eight factors with eigen values greater than one were retained for the causes arising outside the working situation subscale. The percentage of variance accounted for was $62.15 \%$.

The factors indicate the following:

- Factor 1 indicates that fire-fighters often feel that their everyday financial obligations and the general economic situation in the country make life exceptionally difficult for them. This factor further indicates that fire-fighters often feel that the phase of life in which they find themselves and the family crises that are common during this phase have an adverse effect on their lives.

- Factor 2 indicates that fire-fighters employed by the metropolitan municipality (emergency services) often feel dissatisfied with working clothes, working hours, conditions of employment, communication channels with respect to grievances and complaints, rules regarding transfers, the termination of employment and other regulations involving personnel matters. This factor further indicates that fire-fighters often feel that the metropolitan municipality (emergency services) as a whole does not function satisfactorily owing to the poor state of the municipality, the lack of confidence in employees and ineffective leadership styles.

- Factor 3 indicates that fire-fighters often feel in their everyday lives that social situations with friends and relatives are difficult to handle.

- Factor 4 indicates that fire-fighters in emergency services often feel dissatisfied with physical working conditions and job equipment.

- Factor 5 indicates that fire-fighters often feel in their everyday lives that too few recreational facilities are made available to them.

- Factor 6 indicates that fire-fighters often feel in their everyday lives that family stress caused by, for example, death, illness and strife have an adverse effect on their lives.

- Factor 7 indicates that fire-fighters often feel in their everyday lives that rapidly changing technology poses a problem for them.

- Factor 8 indicates that fire-fighters often feel in their everyday lives that the state of their health does not allow them to do what they would like to do.

Organisational functioning: Two factors with eigen values greater than one were retained for the organisational functioning subscale. The percentage of variance accounted for was $60.24 \%$.

The factors indicate the following:

- Factor 1 indicates that fire-fighters in emergency services often feel that management does not believe that firefighters are hard-working and reliable.

- Factor 2 indicates that fire-fighters often feel in their everyday lives that their own views differ from those of other people and that they are not able to talk to their supervisors when they need to.

Task characteristics: Five factors with eigen values greater than one were retained for the task characteristics subscale. The percentage of variance accounted for was $56.22 \%$. 
Factor loadings for the subscales of the Experience of Work and Life Circumstances Questionnaire

\begin{tabular}{|c|c|c|c|c|c|c|c|c|c|c|c|c|c|c|c|}
\hline \multicolumn{2}{|c|}{ SUBSCALE 1} & \multicolumn{2}{|c|}{ SUBSCALE 2} & \multicolumn{2}{|c|}{ SUBSCALE 3} & \multicolumn{2}{|c|}{ SUBSCALE 4} & \multicolumn{2}{|c|}{ SUBSCALE 5} & \multicolumn{2}{|c|}{ SUBSCALE 6} & \multicolumn{2}{|c|}{ SUBSCALE 7} & \multicolumn{2}{|c|}{ SUBSCALE 8} \\
\hline Item & Loading & Item & Loading & Item & Loading & Item & Loading & Item & Loading & Item & Loading & Item & Loading & Item & Loading \\
\hline & Factor 1 & & Factor 1 & & Factor 1 & & Factor 1 & & Factor 1 & & Factor 1 & & Factor 1 & & Factor 1 \\
\hline 26 & 0.82 & 9 & 0.58 & 41 & 0.78 & 8 & 0.72 & 23 & 0.74 & 26 & 0.79 & 50 & 0.77 & 49 & 0.78 \\
\hline 29 & 0.75 & 11 & 0.55 & 45 & 0.72 & 5 & 0.64 & 22 & 0.71 & 33 & 0.76 & 53 & 0.69 & 16 & 0.74 \\
\hline 15 & 0.73 & 10 & 0.54 & 1 & 0.70 & 3 & 0.57 & 37 & 0.70 & 51 & 0.71 & 15 & 0.69 & 35 & 0.72 \\
\hline 12 & 0.68 & 8 & 0.53 & 40 & 0.69 & 27 & 0.57 & 34 & 0.70 & 11 & 0.70 & 30 & 0.68 & 2 & 0.59 \\
\hline 8 & 0.55 & 15 & 0.52 & 18 & 0.57 & 6 & 0.41 & 9 & 0.69 & 10 & 0.49 & 31 & 0.64 & 36 & 0.53 \\
\hline 21 & 0.50 & 14 & 0.52 & & Factor 2 & & Factor 2 & 29 & 0.68 & & Factor 2 & 44 & 0.54 & & Factor 2 \\
\hline 38 & 0.49 & 5 & 0.51 & 21 & 0.86 & 46 & 0.84 & 24 & 0.62 & 48 & 0.83 & 14 & 0.53 & 32 & 0.73 \\
\hline \multirow[t]{2}{*}{17} & 0.43 & 6 & 0.50 & 52 & 0.86 & 47 & 0.77 & & & 12 & 0.59 & & & 7 & 0.69 \\
\hline & Factor 2 & 20 & 0.48 & & & 39 & 0.45 & & & 43 & 0.54 & & & 38 & 0.69 \\
\hline 30 & 0.68 & 7 & 0.48 & & & & Factor 3 & & & & & & & 25 & 0.64 \\
\hline 39 & 0.65 & 18 & 0.47 & & & 19 & 0.71 & & & & & & & 13 & 0.61 \\
\hline 24 & 0.64 & 4 & 0.47 & & & 20 & 0.70 & & & & & & & 36 & 0.42 \\
\hline 23 & 0.48 & 17 & 0.47 & & & 17 & 0.56 & & & & & & & & \\
\hline 22 & 0.46 & 13 & 0.46 & & & & Factor 4 & & & & & & & & \\
\hline \multirow[t]{2}{*}{40} & 0.40 & 19 & 0.43 & & & 28 & 0.68 & & & & & & & & \\
\hline & Factor 3 & 21 & 0.43 & & & 27 & 0.60 & & & & & & & & \\
\hline 3 & 0.66 & & Factor 2 & & & & Factor 5 & & & & & & & & \\
\hline 1 & 0.65 & 7 & 0.60 & & & 42 & 0.60 & & & & & & & & \\
\hline 25 & 0.58 & 1 & 0.58 & & & 4 & 0.80 & & & & & & & & \\
\hline 2 & 0.58 & 18 & 0.45 & & & 6 & 0.43 & & & & & & & & \\
\hline 24 & 0.47 & 17 & 0.42 & & & 3 & 0.41 & & & & & & & & \\
\hline \multirow[t]{2}{*}{4} & 0.45 & & Factor 3 & & & & & & & & & & & & \\
\hline & Factor 4 & 14 & 0.57 & & & & & & & & & & & & \\
\hline 16 & 0.65 & 6 & 0.44 & & & & & & & & & & & & \\
\hline 17 & 0.56 & 15 & 0.40 & & & & & & & & & & & & \\
\hline 20 & 0.51 & 21 & 0.40 & & & & & & & & & & & & \\
\hline 23 & 0.51 & & Factor 4 & & & & & & & & & & & & \\
\hline 9 & 0.46 & 2 & 0.54 & & & & & & & & & & & & \\
\hline \multirow[t]{2}{*}{18} & 0.44 & 22 & 0.44 & & & & & & & & & & & & \\
\hline & Factor 5 & & Factor 5 & & & & & & & & & & & & \\
\hline 35 & 0.73 & 23 & 0.53 & & & & & & & & & & & & \\
\hline 33 & 0.73 & 11 & 0.41 & & & & & & & & & & & & \\
\hline 34 & 0.56 & & Factor 6 & & & & & & & & & & & & \\
\hline \multirow[t]{2}{*}{11} & 0.50 & 2 & 0.51 & & & & & & & & & & & & \\
\hline & Factor 6 & 8 & 0.45 & & & & & & & & & & & & \\
\hline 27 & 0.68 & & Factor 7 & & & & & & & & & & & & \\
\hline 14 & 0.64 & 12 & 0.68 & & & & & & & & & & & & \\
\hline 32 & 0.58 & 1 & 0.42 & & & & & & & & & & & & \\
\hline & Factor 7 & & Factor 8 & & & & & & & & & & & & \\
\hline 6 & 0.74 & 16 & 0.50 & & & & & & & & & & & & \\
\hline 5 & 0.71 & 5 & 0.48 & & & & & & & & & & & & \\
\hline & Factor 8 & 20 & 0.47 & & & & & & & & & & & & \\
\hline 28 & 0.58 & & & & & & & & & & & & & & \\
\hline 40 & 0.53 & & & & & & & & & & & & & & \\
\hline 37 & 0.51 & & & & & & & & & & & & & & \\
\hline 7 & 0.44 & & & & & & & & & & & & & & \\
\hline & Factor 9 & & & & & & & & & & & & & & \\
\hline 19 & 0.78 & & & & & & & & & & & & & & \\
\hline 10 & 0.51 & & & & & & & & & & & & & & \\
\hline & Factor 10 & & & & & & & & & & & & & & \\
\hline 13 & 0.80 & & & & & & & & & & & & & & \\
\hline & Factor 11 & & & & & & & & & & & & & & \\
\hline 36 & 0.75 & & & & & & & & & & & & & & \\
\hline
\end{tabular}

Factor loadings larger than 0.40 are reported. 
The factors indicate the following:

- Factor 1 indicates that fire-fighters often feel irritated in their work.

- $\quad$ Factor 2 indicates that fire-fighters in emergency services often feel unable to display initiative and to become involved in different tasks.

- $\quad$ Factor 3 indicates that fire-fighters in emergency services often feel that they cannot perform their tasks without conflict or without straining their relationships with colleagues as a result of the nature of their work.

- Factor 4 indicates that fire-fighters in emergency services often feel that their tasks cannot be performed without continued and intense concentration and that they lack sufficient knowledge and the necessary information to do their work.

- $\quad$ Factor 5 indicates that fire-fighters in emergency services often feel that they cannot perform their tasks without being on their feet for long periods, lifting heavy objects or working in a bent, crouching or otherwise uncomfortable position.

Physical working conditions and job equipment: One factor with an eigen value greater than one was retained for the physical working conditions and job equipment subscale. The percentage of variance accounted for was $47.81 \%$. This factor indicates that firefighters in emergency services often feel that the job equipment at their disposal is not sufficient and that their physical working conditions are inadequate for the type of work that they do.

Career matters: Two factors with eigen values greater than one were retained for the career matters subscale. The percentage of variance accounted for was $51.63 \%$.

The factors indicate the following:

- Factor 1 indicates that fire-fighters in emergency services often feel that their abilities and skills are not developed and that they are not making any progress in their careers.

- $\quad$ Factor 2 indicates that fire-fighters in emergency services often feel that their posts are essential and will be retained. This factor further indicates that fire-fighters often feel dissatisfied with their promotions.

Social matters: One factor with an eigen value greater than one was retained for the social matters subscale. The percentage of variance accounted for was $42.94 \%$. This factor indicates that fire-fighters in emergency services often feel that they are not able to maintain good relationships with their supervisors and healthy social relationships with others.

Remuneration, fringe benefits and personnel policy: Two factors with eigen values greater than one were retained for the remuneration, fringe benefits and personnel policy subscale.

The percentage of variance accounted for was $52.05 \%$.

The factors indicate the following:

- $\quad$ Factor 1 indicates that fire-fighters in emergency services often feel that the regulations regarding personnel matters are not satisfactory.

- $\quad$ Factor 2 indicates that fire-fighters in emergency services often feel that their salaries are not adequate to motivate them to work hard at all times.

\section{Reliability of the Hopkins Symptom Checklist}

Internal-consistency reliabilities of the subscales of the Hopkins Symptom Checklist were computed and the results are presented in Table 4. Alpha coefficients ranging from 0.73 to 0.86 were obtained.

Varimax rotations to simple structure were subsequently carried out. Factor loadings greater than 0.4 were used as cutoff points and only such values are reported in Table 6.
TABLE 4

Internal-consistency reliabilities of the subscales of the Hopkins Symptom Checklist

\begin{tabular}{lr}
\hline SUBSCALES & CRONBACH ALPHA COEFFICIENT \\
\hline Somatic symptoms & 0.87 \\
Obsessive-compulsive behaviour & 0.76 \\
Interpersonal sensitivity & 0.79 \\
Depression & 0.85 \\
Anxiety & 0.74 \\
\hline
\end{tabular}

TABLE 5

Percentage of variance explained by the factors extracted from the subscales of the Hopkins Symptom Checklist

\begin{tabular}{lrr}
\hline SUBSCALES & $\begin{array}{r}\text { NUMBER OF } \\
\text { FACTORS } \\
\text { RETAINED BY } \\
\text { THE MINEIGEN } \\
\text { CRITERION }\end{array}$ & $\begin{array}{r}\text { CUMULATIVE } \\
\text { PERCENTAGE OF } \\
\text { THE PROPORTION }\end{array}$ \\
\hline Somatic symptoms & 2 & 54.64 \\
Obsessive-compulsive & 2 & 54.91 \\
behaviour & 2 & 63.13 \\
Interpersonal sensitivity & 2 & 50.45 \\
Depression & 2 & 53.73 \\
Anxiety & 2 & \\
\hline
\end{tabular}

Construct validity of the Hopkins Symptom Checklist

Table 5 indicates the number of factors with eigen values greater than one retained by the MINEIGEN criterion as well as the proportion of the variance explained by each subscale of the questionnaire.

Somatic symptoms: Two factors with eigen values greater than one were retained for the somatic subscales. The percentage of variance accounted for was $54.64 \%$.

The factors indicate the following:

- Factor 1 indicates that fire-fighters often experience a numbness and weakness in certain parts of their bodies.

- Factor 2 indicates that fire-fighters often experience headaches and dizziness.

Obsessive-compulsive behaviour: Two factors with eigen values greater than one were retained for the obsessive-compulsive behaviour subscale. The percentage of variance accounted for was $54.91 \%$.

The factors indicate the following:

- Factor 1 indicates that fire-fighters often struggle to concentrate on their work and find it difficult to remember things.

- $\quad$ Factor 2 indicates that fire-fighters often experience that they are forced to do things slowly to ensure that they are correctly done. This factor further indicates that they must frequently check and recheck what they are doing.

Interpersonal sensitivity: Two factors with eigen values greater than one were retained for the interpersonal sensitivity subscale. The percentage of variance accounted for was $63.13 \%$.

The factors indicate the following:

- Factor 1 indicates that fire-fighters often experience that people are unfriendly or do not like them. This factor further indicates that they often feel that people do not understand them or tend to be unsympathetic.

Anxiety: Two factors with eigen values greater than one were retained for the anxiety subscale. The percentage of variance accounted for was $53.73 \%$.

The factors indicate the following:

- Factor 1 indicates that fire-fighters often feel nervous and that they are afraid without any reason.

- Factor 2 indicates that fire-fighters often avoid certain places or activities because these make them afraid and they often feel tense or ready for action. 
TABLE 6

Factor loadings for the subscales of the Hopkins Symptom Checklist

\begin{tabular}{|c|c|c|c|c|c|c|c|c|c|}
\hline \multicolumn{2}{|c|}{ SUBSCALE 1} & \multicolumn{2}{|c|}{ SUBSCALE 2} & \multicolumn{2}{|c|}{ SUBSCALE 3} & \multicolumn{2}{|c|}{ SUBSCALE 4} & \multicolumn{2}{|c|}{ SUBSCALE 5} \\
\hline Item & Loading & Item & Loading & Item & Loading & Item & Loading & Item & Loading \\
\hline & Factor 1 & & Factor 1 & & Factor 1 & & Factor 1 & & Factor 1 \\
\hline 39 & 0.81 & 42 & 0.82 & 28 & 0.79 & 41 & 0.71 & 2 & 0.80 \\
\hline 43 & 0.80 & 6 & 0.79 & 27 & 0.76 & 18 & 0.71 & 12 & 0.80 \\
\hline 45 & 0.77 & 38 & 0.76 & 26 & 0.75 & 21 & 0.68 & 16 & 0.66 \\
\hline 40 & 0.72 & 34 & 0.65 & 31 & 0.74 & 13 & 0.63 & 30 & 0.47 \\
\hline 32 & 0.64 & 20 & 0.59 & & Factor 2 & 23 & 0.62 & & Factor 2 \\
\hline 36 & 0.62 & & Factor 2 & 8 & 0.86 & 24 & 0.53 & 37 & 0.80 \\
\hline \multirow[t]{2}{*}{19} & 0.52 & 29 & 0.80 & 5 & 0.79 & 22 & 0.48 & 44 & 0.65 \\
\hline & Factor 2 & 33 & 0.79 & 17 & 0.74 & 15 & 0.42 & 25 & 0.56 \\
\hline 1 & 0.75 & 7 & 0.59 & & & 4 & 0.42 & 30 & 0.47 \\
\hline 3 & 0.66 & & & & & & Factor 2 & & \\
\hline 10 & 0.66 & & & & & 14 & 0.85 & & \\
\hline 19 & 0.53 & & & & & 22 & 0.63 & & \\
\hline 9 & 0.48 & & & & & 15 & 0.55 & & \\
\hline \multirow[t]{3}{*}{32} & 0.44 & & & & & 11 & 0.54 & & \\
\hline & & & & & & 4 & 0.45 & & \\
\hline & & & & & & 24 & 0.43 & & \\
\hline
\end{tabular}

Factor loadings larger than 0.40 are reported.

\section{DISCUSSION}

The aim of this study was to investigate whether the psychometric properties demonstrated by the Experience of Work and Life Circumstances Questionnaire and the Hopkins Symptom Checklist were favourable enough to recommend the use of these questionnaires for fire-fighters. The magnitudes of the Cronbach alpha coefficients for the subscales of both questionnaires were within an acceptable range for the sample of fire-fighters. With regard to reliability, one may thus conclude that the two questionnaires met the standard required for psychometric instruments.

\section{Experience of Work and Life Circumstances Questionnaire}

Eleven factors with eigen values greater than one were retained for the stress level subscale. These psychological job demands included factors such as aggression, being afraid, uncertainty, a lack of support, a lack of motivation, emotional disturbances, conflict, overload, feelings of guilt and dependence on others, acceptance of things as they are, and being wary of colleagues.

Eight factors with eigen values greater than one were retained for the causes arising outside the work situation subscale. The high demands and low decision control included factors such as financial obligations, dissatisfaction involving personnel matters, difficult interpersonal relationships, dissatisfaction with physical working conditions and job equipment, limited recreational facilities, family stress, rapidly changing technology, and health status.

Two factors with eigen values greater than one were retained for the organisational functioning subscale. These psychological job demands include sub-factors such as that management does not believe that fire-fighters are hard-working and reliable and that supervisors are not approachable. Five factors with eigen values greater than one were retained for the task characteristics subscale. The high demands and low decision latitude include factors such as irritation, limited opportunities to display initiative, strain with colleagues, a lack of sufficient knowledge and information, and physical exhaustion.
One factor with eigen values greater than one was retained for the physical working conditions and job equipment subscale. The psychological job demand includes the factor that job equipment is not sufficient and that physical working conditions are inadequate for the type of work.

Two factors with eigen values greater than one were retained for the career matters subscale. The high demands and low decision control include factors such as a lack of career advancement and dissatisfaction with promotion opportunities.

One factor with eigen values greater than one was retained for the social matters subscale. A heavy psychological job demand includes the factor that fire-fighters feel that they are not able to maintain good relationships with their supervisors and healthy social relationships.

Two factors with eigen values greater than one were retained for the remuneration, fringe benefits and personnel policy subscale. The high demands and low decision latitude include factors such as regulations pertaining to personnel matters not being satisfactory and inadequate salaries. These results provide evidence for the validity of the subscales of the Experience of Work and Life Circumstances Questionnaire.

\section{Hopkins Symptom Checklist}

Two factors with eigen values greater than one were retained for the somatic subscale. These psychological job demands include factors such as numbness and weakness in certain body parts, headaches, and dizziness.

Two factors with eigen values greater than one were retained for the obsessive-compulsive behaviour subscale. The high demands and low decision control include factors such as concentration problems and difficulty in remembering things, and the checking and rechecking of behavioural actions.

Two factors with eigen values greater than one were retained for the interpersonal sensitivity subscale. The psychological job demands include sub-factors such as unfriendliness and a lack of sympathy, and agitation and criticism. 
Two factors with eigen values greater than one were retained for the depression subscale. The high demands and low decision latitude include factors such as desperation, blame, loneliness, and despondence and sorrow.

Two factors with eigen values greater than one were retained for the anxiety subscale. These psychological job demands include factors such as nervousness, being afraid, avoiding certain places and tension. These results provide evidence for the validity of the subscales of the Hopkins Symptom Checklist.

\section{Conclusions and recommendations}

The aim of this research was to investigate the reliability and construct validity of the Experience of Work and Life Circumstances Questionnaire and the Hopkins Symptom Checklist as measured among fire-fighters. Behavioural researchers and industrial psychologists should take note of the findings of this study, namely that the Experience of Work and Life Circumstances Questionnaire and the Hopkins Symptom Checklist are suitable for the evaluation of job and family stress for this specific sample of fire-fighters in the South African context. Given the nature of the sample, it may be reasonable on extra-statistical grounds to generalise these findings to the population of South African fire-fighters because the large sample consisted of all the fire-fighters in one metropolitan area who were not working shifts at the time of testing. One would assume that the working conditions of fire-fighters would not vary much among various areas. One should nevertheless keep in mind that factors relating to superiors and peers could differ among areas.

The research findings add to existing knowledge about the psychometric properties of the Experience of Work and Life Circumstances Questionnaire and the Hopkins Symptom Checklist, specifically about job and family stress. It is recommended that industrial psychologists make use of these measuring instruments during counselling to enhance the psychological well-being of fire-fighters and their families.

\section{REFERENCES}

Arterburn, T.R. (2001). Disaster response: At ground zero. Law $\mathcal{E}$ Order, 49(11), 97-100.

Barlow, D.H. (2002). Abnormal psychology: An integrative approach. Belmont: Wadsworth/Thomson.

Beaton, R., Johnson, L.C., Infield, S., Ollis, T., \& Bond, G. (2001). Outcomes of a leadership intervention for a metropolitan fire department. Psychological Reports, 88(3), 1049-1066.

Bless, C., \& Higson-Smith, C. (2000). Fundamentals of social research methods: An African perspective. Cape Town: Juta.

Cattell, R.B., Eber, H.W., \& Tatsuoka, M.M. (1970). Handbook for the sixteen personality factor questionnaire (16-PF). Champaign: IPAT.

Catellano, C., \& Plionis, E. (2006). Comparative analysis of three crisis intervention models applied to law enforcement first responders during 9/11 and hurricane Katrina. Brief Treatment and Crisis Intervention, 6(4), 326.

Daniels, K. (1999). Coping and the job demands-control-support model: An exploratory study. International Journal of Stress Management, 6(2), 125-144.

Davison, G.C., Neale, J.M., \& Kring, A.M. Abnormal psychology. New York: John Wiley.

De Jonge, J., Dollard, M.F., Dormann, C., Le Blanc, P.M., \& Houtman, L.D. (2000). The demand-control model: Specific demands, specific control, and well-defined groups. International Journal of Stress Management, 7(4), 269-287.

Derogatis, L.R., Lipman, R.S., Rickles, K., Uhlenhuth, E.H., \& Covi, L. (1974). The Hopkins Symptom Checklist (HSCL): A self-report symptom inventory. Behavioural Science, 19, $1-15$.
Elliot, D.L., Goldberg, L., Duncan, T.E., \& Kuehl, K.S. (2004). The PHLAME firefighters' study: Feasibility and findings. American Journal of Health Behaviour, 28(1), 13-23.

Fishkin, G.L. (1991). The dynamics of fire-fighter stress. American Fire Journal, 16, 21-33.

Fishkin, G.L. (1992). Firefighters and depression: Identification and treatment. American Fire Journal, 12.

Fontana, D. (1994). Problems in practice: Managing stress. Great Britain: The British Psychological Society and Routledge.

Fouché, F.A., \& Grobbelaar, P.E. (1971). Handleiding vir die PHSFverhoudingevraelys. Pretoria: Human Sciences Research Council.

Gmelch, W.H. (1982). Beyond stress to effective management. New York: Wiley.

Gmelch, W.H., \& Chan, W. (1994). Thriving on stress for success. California: Corwin.

He, N., Zhao, J., \& Archbold, C.A. (2002). Gender and police stress: The convergent and divergent impact of work environment, work-family conflict, and stress coping mechanisms of female and male police officers. Policing, 25(4), 687-709.

Jerling, A. (2002). EMS personnel need no longer 'simply cope': Well-being feature. Emergency Services SA, 23(5), 22-24.

Kaminsky, M., McCabe, O.L., Langlieb, A.M., \& Everly Jr, G.S. (2007). An evidence-informed model of human resistance, resilience, and recovery: The Johns Hopkins' outcomedriven paradigm for disaster mental health services. Brief Treatment and Crisis Intervention, 7(1), 1-11.

Karasek, R. (1979). Healthy work: Stress, productivity, and the reconstruction of working life. New York: Basic Books.

Lemanski, C. (2003). Psychological first aid: After debriefing. Fire Engineering, 156(6), 73-75.

Linienfeld, S.O. (1998). Looking into abnormal psychology: Contemporary readings. Pacific Grove: Brooks/Cole.

Miller, L. (2007). Police families: Stresses, syndromes, and solutions. The American Journal of Family Therapy, 35(1), 21.

Mitchell, J.T., \& Bray, G.P. (1990). Emergency services stress: Guidelines for preserving the health and careers of emergency services personnel. Englewood Cliffs: Prentice Hall.

Monnier, J., Cameron, R.P., Hobfoll, S.E., \& Gribble, J.R. (2000). Direct and crossover effects of prosocial and antisocial coping behaviours. Journal of Family Psychology, 14(4), 570584.

Morash, M., Haarr, R., \& Kwak, D.H. (2006). Multilevel influence on police stress. Journal of Contemporary Criminal Justice, 22(1), 26.

Nevid, J.S., Rathus, S.A., \& Greene, B. (2003). Abnormal psychology in a changing world. Upper Saddle River: Prentice Hall.

Nevid, J.S., Rathus, S.A., \& Greene, B. (2005). Abnormal psychology in a changing world media and research update (5th edn.). Upper Saddle River: Prentice Hall.

North, C.S. (2002). Report: Critical incident stress needs managed. Occupational Hazards, 64(8), 20.

Nunnally, J.C. (1978). Psychometric theory. New York: McGrawHill.

Peltzer, K. (2001). Stress and traumatic symptoms among police officers at a South African police station. Acta Criminologica, 14(3), 52-56.

Perry, M. (1999). Spousal support. Sheriff, 51(3), 24-25.

Pike, A. (2003). Dealing with stress: Health and safety. Emergency Services SA, 24(5), 20-21.

Piltch, C.A., Walsh, D.C., Mangione, T.W., \& Jennings, S.E. (1994). In G.P. Keita \& J.J. Hurrell Jr (Eds.), Gender, work, and mental distress in an industrial labour force: An expansion of Karasek's job strain model (pp. 39-54). Washington: American Psychological Association.

Plug, C., Meyer, W.F., Louw, D.A., \& Gouws, L.A. (1991). Psychological dictionary. Johannesburg: McGraw-Hill.

Raftery, A.E., Tanner, M.A., \& Wells, M.T. (2002). Statistics in the 21st century. Boca Raton: Chapman \& Hall/CRC. 
Regehr, C., Johanis, D., Dimitropoulos, G., Bartram, C., \& Hope G. (2003). The police officer and the public inquiry: A qualitative inquiry into the aftermath of workplace trauma. Brief Treatment and Crisis Intervention, 3(4), 383.

Roberts, N.A., \& Levenson, R.W. (2001). The remains of the workday: Impact of job stress and exhaustion on marital interaction in police couples. Journal of Marriage and the Family, 63(4), 1052-1067.

Rogers, J.R. (2007). Disaster response and the mental health counselor. Journal of Mental Health Counseling, 29(1), 1-3.

Sauter, S., Murphy, L., \& Hurrell Jr, J.J. (1990). Prevention of workrelated psychological disorders. American Psychologist, 45, $1146-1158$.

Seedat, S., La Grange, H., Niehaus, D., \& Stein, D.J. (2003). Stress and resilience in South African firefighters. South African Medical Journal, 93(4), 236-238.

Shakespeare-Finch, J., Smith, S., \& Obst, P. (2002). Trauma, coping resources, and family functioning in emergency services personnel: A comparative study. Work $\mathcal{E}$ Stress, 16(3), 275-282.

Smith, D.L., Manning, T.S., \& Petruzzello, S.J. (2001). Effect of strenuous drills on cardiovascular and psychological responses of recruit firefighters. Ergonomics, 44(3), 244-254.

Stockton, D. (2003). Never give up. Law $\mathcal{E}$ Order, 51(9), 88-96.

Sutherland, V.J., \& Cooper, C.L. (1990). Understanding stress: A psychological perspective for health professionals. London: Chapman \& Hall.
Torres, S., Maggard, D.L., \& Torres, C. (2003). Preparing families for the hazards of police work. The Police Chief, 70(10), 108.

Ussery, W.J., \& Waters, J.A. (2006). COP-2-COP hotlines: Programs to address the needs of first responders and their families. Brief Treatment and Crisis Intervention, 6(1), 66.

Van der Doef, M., \& Maes, S. The job demand-control (-support) model and psychological well-being: A review of 20 years of empirical research. Work and Stress, 13(2), 87-114.

Van Graan, F. (1981). Werkspanning: 'n Bedryfsielkundige ondersoek. Unpublished DCom dissertation, Potchefstroom University for Christian Higher Education, Potchefstroom, South Africa.

Van Zyl, E.S., \& Van der Walt, H.S. (1991). Manual for the experience of work and life circumstances questionnaire. Pretoria: Human Sciences Research Council.

Volpe, J.F. (2000). A guide to effective stress management. Law $\mathcal{E}$ Order, 48(10), 183-186.

Waters, J.A. (2002). Moving forward from September 11: A stress/crisis/trauma response. Brief Treatment and Crisis Intervention, 2(1), 55.

Wiese, L., Rothmann, S., \& Storm, K. (2003). Coping, stress and burnout in the South African police service in KwaZuluNatal. South African Journal of Industrial Psychology, 29(4), 71-80. 